\title{
Pesan, Tanda, dan Makna dalam Studi Komunikasi
}

\author{
Alimuddin A. Djawad \\ STKIP PGRI Banjarmasin \\ Jl. Sultan Adam, Komp. H. Iyus, Banjarmasin
}

\begin{abstract}
Abstrak
Tulisan ini bertujuan untuk mengkaji keteraitan pesan, tanda, dan makna dalam komunikasi. Pesan merupakan sesuatu yang penting sehingga dibutuhkan media perantara agar diterima oleh penerima (receiver). Dalam kegiatan komunikasi, pesan diubah dalam wujud tanda (sign). Hal ini, menunjukkan bahwa pesan dan tanda memiliki keterkaitan. Di sisi lain, makna merupakan hasil dari penandaan sehingga sifatnya tidak mutlak dan statis.
\end{abstract}

Kata Kunci: pesan, tanda, makna, studi komunikasi

\section{PENDAHULUAN}

Ihwal pesan, tanda, dan makna merupakan komponen yang sangat mendasar dalam dunia komunikasi. Sementara komunikasi dalam perspektif semiotika merupakan pembangkitan makna (the generation of meaning). Mulyana dalam Vera (2014) menegaskan bahwa semiotika sama saja dengan ilmu komunikasi. Keduanya menyangkut studi tentang hubungan antara simbol dengan yang disimbolkan.

Secara sederhana istilah semiotika dapat dijelaskan sebagai ilmu yang mengkaji tentang tanda dan makna tanda. Tanda itu sendiri merupakan basis dari seluruh komunikasi. Suatu tanda akan menandakan sesuatu selain dirinya sendiri. Dalam kaoitan ini, Morris (dalam Levinsan, 1983:1) memperkenalkan tiga konsep dasar, yaitu sintaksis (syntax), semantik (semantics), dan pragmatik (pragmatics). Sintaksis adalah kajian tentang hubungan formal antartanda; semantik adalah hubungan tanda dengan objek tanda; dan pragmatik berkenaan dengan hubungan tanda dengan penafsir tanda itu. Ketiga bidang itu memperlakukan dan mempelajari tanda secara berbeda-beda.

Dalam semiotika yang menjadi dasar adalah konsep tentang tanda. Tidak hanya bahasa dan sistem komunikasi yang tersusun oleh tanda-tanda melainkan dunia itu sendiri sejauh terkait pikiran manusia seluruhnya terdiri atas tanda-tanda. Tanpa tanda-tanda, manusia tidak akan bisa menjalin hubungan dengan realitas. Semiotika merupakan studi atau metode untuk mengkaji tanda dalam suatu konteks yang dapat dimaknai.

Berkenaan dengan tanda akan dikemukakan pandangan dua orang tokoh sentral dalam semiotik, yakni Charles Sander Pierce dan Ferdinand de Saussure. Kedua tokoh itu dalam semiotik memiliki kesamaan, meskipun bersandar pada prinsip semiotik pada landasan yang berbeda hingga melahirkan konsep yang berbeda pula. Perbedaan mendasar kedua tokoh itu adalah pada aspek penerapan konsepkonsep semiotika yang didasarkan pada latar belakang keilmuan masing-masing. 
Pierce merupakan pakar bidang linguistik dan logika, sedangkan Saussure adalah seorang pakar dalam bidang linguistik modern.

Dalam perkembangannya ada dua istilah yang akhirnya diterima sebagai sinonim, yaitu semiotika dan simiologi. Kedua istilah itu kemudian digunakan untuk mengidentifikasi adanya dua tradisi semiotika. Istilah semiotika diperkenalakan oleh Pierce yang kemudian dominan dalam studi tentang tanda. Sementara itu, Saussure yang dikenal sebagai seorang linguis modern menggunakan istilah semiologi untuk semiotika. Dalam konsep Saussure, semiologi merupakan ilmu yang mengkaji tandatanda di dalam masyarakat.

Rumusan tentang semiologi secara tegas dikemukakan Paul de Man (dalam Wolfreis, 1999:330) bahwa semiologi merupakan studi tentang tanda sebagai penanda tidak mempertanyakan makna kata, tetapi bagaimana kata bermakna (bandingkan Rusmana, 2014:22); Sobur, 2013:11-12; Santoso, 1993:10). Dalam lingkup semiologi ada tiga ranah, yakni tanda dalam dirinya, kode-kode atau sistem tempat tanda itu diorganisasikan, dan kebudayaan tempat kode-kode dan tanda-tanda itu beroperasi.

Selanjutnya, dalam paparan berikut akan difokuskan untuk membahas tentang pesan, tanda, dan makna yang tentu saja memiliki keterkaitan satu sama lain. Ketiga hal itu akan ditelaah berdasarkan teori semiotika terutama yang dipopulerkan oleh Pierce dan Saussure sebagai perintisnya.

\section{PEMBAHASAN}

\section{Pesan, Tanda, Makna, dan Keterkaitannya \\ 1.1 Pesan}

Pada hakikatnya pesan merupakan sesuatu yang disampaikan, baik lisan maupun tertulis yang berupa informasi atau komunikasi. Dalam hal ini, disadari bahwa dalam proses komunikasi, pesan sangat penting. Oleh sebab itu, agar pesan dapat diterima dari pengguna ke pengguna lain, maka proses pengiriman atau penyampaian pesan membutuhkan suatu media perantara. Media ini dimaksudkan supaya pesan yang dikirimkan oleh sumber (source) dapat diterima dengan baik oleh penerima (receiver). Dalam proses pengiriman pesan itu hendaknya dikemas untuk mengatasi gangguan yang muncul dalam transmisi pesan sehingga tidak menimbulkan perbedaan makna yang diterima oleh penerima (receiver).

Secara umum, jenis pesan terbagi atas pesan verbal dan pesan nonverbal. Pesan verbal adalah jenis pesan yang penyampaiannya menggunakan kata-kata, dan dapat dipahami isinya oleh penerima berdasarkan apa yang didengarnya, sedangkan pesan nonverbal adalah jenis pesan yang penyampaiannya tidak menggunakan katakata secara langsung tetapi dapat dipahami isinya oleh penerima berdasarkan gerakgerik, tingkah laku, mimik wajah, atau ekspresi muka pengirim pesan.

Perlu ditambahkan bahwa pesan memiliki sifat abstrak. Karena itu, untuk mengkonkrtitkan, maka harus diubah menjadi lambang-lambang komunikasi. Rangkaian lambang-lambang komunikasi dalam satuan sistem sehingga membentuk makna disebut bahasa. Proses mengubah pesan menjadi lambang komunikasi atau kode disebut proses penyedia, dan sarananya disebut alat penyandi (encoder), dan yang mengkomunikasikan pesan disebut komunikator penyandi pesan (encode). Pada 
saat pesan sampai pada komunikasi, rangkaian lambang komunikasi yang membentuk bahasa itu harus diterjemahkan kembali menjadi pesan agar dapat dimaknai oleh komunikan.

Proses mengurai lambang komunikasi kembali pada makna pesan disebut penyandian balik (decoding), dan alatnya disebut alat penyandi balik (decoder). Pemahaman tentang penyajian (encoding) pada komunikator, dan penyandiann balik (decoding) pada komunikasi sangat penting untuk mengkaji pembentukan dan pemaknaan pesan.

Dalam melakukan kegiatan komunikasi tentu saja pesan akan dibuat dalam wujud tanda (sign). Karena itu, tanda bagi Eco (1979) merupakan sarana komunikasi di antara komunikator dan komunikan dalam berkomunikasi untuk mengekspresikan sesuatu. Hal ini, mengindikasikan bahwa pesan dan tanda memiliki keterkaitan karena tanpa tanda, pesan tidak dapat disampaikan. Lebih lanjut, tentang tanda akan dibahas di bawah ini.

\subsection{Tanda}

Tanda merupakan istilah pokok yang dikenal dalam studi semiotika. Berger (2010) menegaskan bahwa tanda adalah segala sesuatu yang dapat digunakan untuk sesuatu yang lain (bandingkan Noth, 2006:79-82; Kaelan, 2009:162). Tanda merupakan objek material, tindakan, atau peristiwa yang dapat diamati secara indrawi. Dalam konteks ini, setiap tanda terdiri atas penanda dan petanda (meminjam istilah Saussure).

Pierce yang berlatar belakang disiplin linguistik dan logika mempopulerkan tiga jenis tanda berdasarkan objeknya yang meliputi ikon, indeks, dan simbol. Ikon adalah tanda yang memperlihatkan hubungan antara penanda dan petandanya yang bersifat bersamaan bentuk alamiah. Dengan kata lain, ikon merupakan hubungan antara tanda dan objek atau acuan yang bersifat mirip, misalnya ngeong untuk bunyi yang dikeluarkan kucing. Indeks adalah tanda yang menunjukkan adanya tanda hubungan alamiah antara tanda dan petanda yang bersifat kausal (hubungan sebab akibat) atau tanda yang langsung mengacu pada kenyataan, misalnya asap indeks dari api. Simbol adalah tanda yang menunjukkan hubungan alamiah antara penanda dan petandanya, hubungan diantaranya bersifat arbitrer atau manasuka, hubungan berdasarkan kesepakatan masyarakat.

Lebih lanjut, Pierce mengemukakan model triadic yang meliputi ground, objek acuan, dan interpretant. Ground adalah sesuatu yang digunakan agar tanda berfungsi. Objek atau acuan adalah yang diacu tanda. Interprentant adalah menunjukkan pada penerima tanda, atau dapat diistilahkan dengan sign.

Proses pemaknaan tanda disebut sebagai proses semiosis. Pierce meyakini bahwa tanda menjadi wakil yang menjelaskan sesuatu. Tanda berfungsi menunjukkan, si penafsirlah yang memaknainya berdasarkan pengalaman masingmasing. Hal ini, didasarkan pada realita bahwa makna sebuah tanda dapat berlaku secara pribadi, sosial, atau bergantung pada konteks tertentu. Dengan singkat dapat dikatakan bahwa tanda adalah sesuatu yang dikaitkan pada seseorang untuk sesuatu dalam beberapa hal atau kapasitas. Tanda itu menunjukkan pada seseorang yakni 
menciptakan tanda di benak seseorang yang disebut interpretant. Tanda tersebut menunjukkan sesuatu, yaitu objeknya.

Berdasarkan interpretant, tanda (sign, represetement) dapat digolongkan menjadi tiga jenis berikut.

1) rheme yaitu tanda yang memungkinkan orang menafsirkan berdasarkan pilihan. Misalnya saja, mata seseorang memerah bisa ditafsirkan baru bangun tidur, mengantuk, sakit mata, atau dalam keadaan merah.

2) dicent sign/dicisign yaitu tanda yang sesuai dengan kenyataan, misalnya ditepi jalan dipasang rambu-rambu sebagai petunjuk bahwa di situ sering terjadi kecelakaan.

3) argument yaitu tanda yang langsung memberikan suatu alasan tentang sesuatu.

Sehubungan dengan tanda, Saussure berpandangan bahwa bahasa itu adalah sistem tanda, dan setiap tanda itu tersusun atas dua bagian, yakni signifier (penanda) dan signified (petanda). Menurut Saussure, bahasa merupakan suatu sistem tanda, dan setiap tanda kebahasaan pada dasarnya menyatakan sebuah konsep dan suatu citra suara (sound image), bukan menyatakan sesuatu dengan sebuah nama. Suara yang muncul dari sebuah kata yang diucapkan merupakan penanda (signifier), sedangkan konsepnya adalah petanda (signified). Kedua unsur itu tidak dapat dipisahkan.

Saussure menyatakan bahwa tanda merupakan kombinasi dari konsep dan citra bunyi (sound image). Hubungan signifier (penanda) yang terdiri atas citra bunyi (semacam kata atau representasi visual) dan signified (petanda) gambaran mental atau konsep tempat bersandarnya citra bunyi. Hubungan anatara signifier dan signified (petanda) membentuk tanda. Huubungan keduanya diistilahkan dengan signification. Atau, dapat dikatakan bahwa signification adalah upaya dalam memberi makna terhadap dunia.

Ihwal tanda yang dijadikan sebagai masalah perbincangan dua orag tokoh besar (Pierce dan Saussure) di atas menarik dicermati. Kedua pakar itu memandang tanda sebagai sesuatu yang sangat penting di dalam kehidupan manusia. Bahkan, bahasa pun yang menjadi sarana komunikasi dalam masyarakatnya merupakan tanda. Dengan tegas Halliday (1979) mengemukakan tesisnya bahwa selain merupakan fakta sosial, bahasa dianggap sebagai semiotik sosial.

Untuk memahami hakikat tanda dalam komunikasi sosial khususnya perlu diperhatikan situasi sosial tertentu sebagai tempat tanda itu digunakan. Situasi-situasi tanda bertalian erat dengan produksi tuturan (bahasa dan pikiran). Akibat perbedaan situasi sosial bisa saja tanda itu menghasilkan penanda yang berbeda meskipun petandanya sama.

Sebagai penutup pembahasan tentang tanda, maka dapat ditegaskan bahwa tanda yang menjadi objek pembicaraan Pierce dan Saussure memiliki perbedaan pemikiran dan pandangan. Pierce memandang tanda sebagai suatu struktur yang cenderung tidak sadar dalam penciptaannya, sedangkan Saussure lebih bertendensi memandang tanda sebagai struktur yang bersifat arbitrer dan konvensional (Danise, 2010:37). Perbedaan pemikiran keduanya berimpilkasi pada teori tanda yang dirumuskan. Pierce memandang tanda sebagai struktur triadik yang terdiri atas tiga dimensi, yaitu representamen (tanda), objek (konsep, benda, gagasan, dst), dan 
interpretant (makna yang diperoleh dari tanda). Sebaliknya, Saussure berteori bahwa tanda terdiri atas signifier (penanda) dan signified (pertanda).

\subsection{Makna}

Dalam kaitannya dengan makna, ada beberapa ahli merumuskan hubungan antara tanda (sign), objek, dan pemakai dalam bentuk hubungan segitiga. Oleh sebab itu, teori segitiga makna (triangle meaning theory) dibuat untuk menjelaskan terjadinya makna. Salah seorang ahli yang menyusun teori segitiga makna adalah Pierce. Menurut tokoh itu, sebuah tanda (sign) yang mengacu kepada sesuatu di luar dirinya, yaitu objek akan mempunyai pengaruh pada pikiran pemakainya karena adanya hubungan timbal balik antarelemen itu.

Jika dihubungkan dengan konsep Saussure mengenai penanda dan pertanda, maka sebenarnya makna lebih dekat pada penanda. Sebab, pada prinsipnya, makna itu merupakan hasil penanda. Hasil operasi penanda itulah yang nantinya memunculkan makna. Makna tidak melekat pada kata-kata tetapi membangkitkan makna dalam pikiran orang. Jadi, tidak ada hubungan langsung antara suatu objek dan simbol yang digunakan untuk mempresentasikannya. Ketika mengatakan "Saya sakit perut", misalnya pengalaman itu nyata, tetapi tidak seorang pun dapat merasakan rasa sakit itu. Hubungan itu diciptakan dalam pikiran pembicara.

Makna bukanlah konsep yang mutlak dan statis yang bisa ditemukan dalam kemasan pesan. Pemaknaan merupakan proses aktif, sehingga para ahli semiotika menggunakan kata kerja seperti menciptakan, membangitkan, atau menegosiasikan itu mengacu pada proses pemaknaan. Makna merupakan hasil interaksi dinamis antara tanda, interprettant, dan objek. Secara historis makna ditempatkan dan mungkin akan berubah seiring dengan perjalanan waktu.

Makna berkaitan dengan tujuan manusia. Contoh lain harus berhati-hati terhadap kawan yang menatap kita, apakah dengan mesra atau dengan tegas. Jika ketiga dimensi tersebut disatukan dalam bentuk segitiga kemudian dikaitkan dengan objeknya. Hal ini, akan melahirkan "teori piramida makna". Hubungan ketiga dimensi di atas dengan objeknya menunjukkan bahwa rujukan atas pemakaian suatu lambang komunikasi didasarkan pada pengalaman dan pendidikan dari pemakaian atas objek yang dirujuk oleh lambang itu. Misalnya saja, ketika mengatakan kata cinta berarti dia merujuk dari pengalaman akal budinya mengenai objek dari istilah cinta untuk menunjukkan bahwa dia menyayangi seseorang,

Dalam konteks linguistik dapat dijelaskan bahwa makna sebuah kata tidak semata-mata tergantung pada referensinya, atau pada aspek maknanya yang lain yang dianggap sebagai sifat khas kata tersebut yang terpisah dari kata-kata lain dalam bahasa yang bersangkutan. Makna sebuah kata ditentukan oleh kehadiran kata yang lain. Bahkan, makna kata bisa diubah oleh kemunculan kata. Sebagian makna dan pemaknaan kata bergantung pada kehadiran kata yang lain dalam bahasa, atau penguasaan penutur akan kata yang fungsi semantisnya berhubungan.

Para ahli semantik semakin menyadari bahwa makna sangat esensial untuk dikaji. Hal inilah yang mengilhami munculnya teori medan makna. Teori itu pertama kali diperkenalkan oleh beberapa sarjana Jerman dan Swiss pada tahun 1920-an dan 1930-an antara lain Ipsen, Jolles, Porziq, dan Trier. Di antara mereka, Trier yang 
dianggap cukup berpengaruh karena telah membuka suatu fase baru dalam sejarah semantik (Lyons,1989:250). Idenya kemudian dikembangkan muridnya, yaitu L. Weisgerber yang secara eksplisit menghubungkan gagasannya dengan gagasan Trier sehingga dikenal teori Trier-Weisgerber. Dalam teori medan makna, dibedakan antara arti dan designasi. Perbedaan antara arti dan designasi dihubungkan dengan pengertian dari Humbold bahwa bahasa menentukan pola-pola pikiran masyarakat yang menggunakannya.

\section{SIMPULAN}

Untuk mengakhiri paparan tentang pesan, tanda, dan makna ini, maka dapat ditegaskan bahwa tanda (sign) adalah sesuatu yang bersifat fisik, bisa dipersepsi indra. Tanda juga mengacu pada sesuatu yang bersifat fisik, bisa dipersepsi indra. Tanda juga mengacu pada sesuatu di luar tanda itu sendiri, dan bergantung pengenalan oleh pemakainya sehingga dapat disebut tanda. Sementara itu, makna merupakan hasil dari penandaan. Makna bukanlah konsep yang mutlak dan statis yang bisa ditemukan dalam pesan begitu saja. Pemaknaan adalah proses aktif untuk memunculkan makna. Karena itu jelas, bahwa pesan, tanda, dan makna memiliki keterkaitan.

\section{Daftar Pustaka}

Berger, Arthur Asa. 2010. Pengantar Semiotika: Tanda-tanda dalam Kebudayaan Kontemporer. Yogyakarta: Tiara Wacana.

Danesi, Marcel. 2010. Pesan, Tanda, dan Makna. Yogyakarta; Jalasutra.

Eco, Umberto. 1979. A Theory of Semiotics. Bloomington: Indiana University Press.

Halliday, M.A.K. 1979. Languange as Social Semiotics: The Social Interpretation of Languange and Meaning. London: Edward Arnold.

Kaelan. 2009. Filsafat Bahasa, Semiotika, dan Hermeneutika. Yogyakarta: Paradigma.

Levinson, C. Stephen. 1983. Pragmatics. Cambridge: Cambridge University Press.

Lyons. 1989. Semantics Volume 1. Cambridge: Cambridge University Press.

Noth, Winfried. 2006. Semiotik. Surabaya: Airlangga University Press.

Rusmana, Dadan. 2014. Filsafat Semiotika. Bandung: Pustaka Setia.

Santoso, Puji. 1993. Ancangan Semiotika dan Pengkajian Susastra. Bandung: Angkasa. 
Sobur, Alex. 2013. Semiotika Komunikasi. Bandung: Rosdakarya.

Vera, Nawiroh. 2014. Semiotika dalam Riset Komunikasi. Bogor: Ghalia Indonesia.

Wolfreis, J. (Peny.). 1999. Literary Theories. New York: New York University Press. 